\title{
Selective Growth of CdTe on Patterned CdTe/Si(211)
}

\author{
T. Seldrum ${ }^{\mathrm{a}}$, R. Bommena ${ }^{\mathrm{b}}$, L. Samain ${ }^{\mathrm{a}}$, J. Dumont ${ }^{\mathrm{a}}$, S. Sivananthan ${ }^{\mathrm{b}}$ and R. Sporken ${ }^{\mathrm{a}, \mathrm{b}}$ \\ ${ }^{\text {a } U n i v e r s i t y ~ o f ~ N a m u r ~-~ F U N D P, ~ D e p a r t m e n t ~ o f ~ P h y s i c s, ~ R u e ~ d e ~ B r u x e l l e s ~ 61, ~ B-5000 ~ N a m u r, ~}$ \\ Belgium \\ ${ }^{\mathrm{b}}$ University of Illinois at Chicago, Microphysics Laboratory, 845 W. Taylor Street, Chicago, IL \\ 60607
}

\begin{abstract}
$\underline{\text { Abstract }}$
We have studied selective growth of cadmium telluride on $\mathrm{Si}(211)$ by molecular beam epitaxy (MBE). Patterned substrates were produced by optical lithography of MBE-grown $\mathrm{CdTe} / \mathrm{As} / \mathrm{Si}(211)$. Photoemission microscopy was used as the main tool to study selective growth. This is very powerful because $\mathrm{Si}$ or $\mathrm{SiO}_{2}$ can be distinguished very easily from areas covered with even small amounts of CdTe due to contrast from workfunction differences. It was found that CdTe grows on $\mathrm{CdTe}$ without sticking on bare $\mathrm{Si}$ areas if the temperature is sufficiently high. Based on analysis of the temperature dependence of the growth rate of CdTe, we suggest that different physisorption energies on $\mathrm{Si}$ and CdTe are the main cause of this selective growth.
\end{abstract}




\section{Introduction}

CdTe or CdZnTe are widely used as buffer layers for the epitaxy of HgCdTe. Among the polar faces of CdTe, only the tellurium-terminated orientations are suitable for the growth of $\mathrm{HgCdTe}$ by $\mathrm{MBE}^{1}$. IR detectors and focal plane arrays require CdTe substrates with high purity and low defect density. Although monocrystalline layers of CdTe have been grown directly on silicon since $1989^{2}$ and successful fabrication of detectors from $\mathrm{HgCdTe}$ grown on such layers has been demonstrated $^{3,4}$, the large lattice mismatch between CdTe and Si (19\%) and the different thermal expansion coefficients continue to be a challenge. Dislocations that appear at the interface between CdTe and Si can propagate into the active layer and lead to a decrease in performance or premature failure of the devices.

Theoretical and experimental studies by Zubia et al. ${ }^{5}$ demonstrated that the use of nanostructures as seeds for selective epitaxy of a semiconductor can result in new relaxation mechanisms that would lead to lower defect density of the grown layer. Guha et al. ${ }^{6}$ have demonstrated defect reduction through MBE growth of III-As compounds on nanosize mesas while Hiramatsu et al. ${ }^{7}$ and others have demonstrated defect reduction through growth of III-nitrides by MOCVD by epitaxial lateral overgrowth starting from nanostructures. Selective growth of CdTe was demonstrated by MOCVD by Bhat and Zhang. ${ }^{8}$

In the present study, we demonstrate that selective growth can be achieved by molecular beam epitaxy on CdTe islands patterned on $\mathrm{Si}(211)$ and we propose a mechanism based on a change of the physisorption energy to explain the selectivity. The CdTe islands patterned on the silicon substrate are micron-size diameter. To characterize these structures, we use mainly in-situ photoelectron emission microscopy (PEEM), X-ray photoemission spectroscopy (XPS), 
scanning electron microscopy (SEM), surface profilometry and Nomarski microscopy.

\section{Experimental details}

We started with the growth of thin layers of CdTe on $\mathrm{Si}(211)$. These layers were then patterend by optical lithography to produce cylindrical islands of CdTe with areas of bare Si between the islands. These patterned layers were then used as templates for selective growth.

For the initial growth of CdTe on $\mathrm{Si}(211)$, the UHV system is composed of an introduction chamber, a preparation chamber (base pressure of $5 \times 10^{-10}$ torr) and a MBE growth chamber (RIBER OPUS 45) equipped with RHEED (base pressure of $8 \times 10^{-10}$ torr). The substrates are 3 inch $\operatorname{Si}(211)$ wafers and are placed on 5 inch molybdenum holders. The flux from the MBE cells is measured with a Bayard-Alpert gauge placed between the cryopanel and the substrate holder. In the preparation and the growth chambers, the temperature is measured with a type- $\mathrm{K}$ thermocouple placed behind the substrate. The real substrate temperature is always lower than the thermocouple reading, but for simplicity, we will quote the thermocouple reading throughout this paper.

After patterning, the height of the CdTe islands is measured ex-situ with a Veeco 8 DekTak step profiler. X-ray diffraction (XRD) is used to determine the crystal structure and scanning electron microscopy (SEM) and scanning Auger microscopy (SAM) to check the homogeneity of the patterned substrates.

Selective growth was studied in an in-situ UHV system that consists of an introduction chamber, an analysis chamber with Auger electron spectroscopy (AES) and photoelectron emission microscopy (PEEM) (base pressure of $6 \times 10^{-11}$ torr) and a RIBER MBE chamber (base pressure of $5 \times 10^{-10}$ torr). The PEEM experiment uses a Hg lamp (energy of $4.9 \mathrm{eV}$ ) and the pictures are 
recorded with a Peltier-cooled CCD camera. The temperature in the in-situ MBE chamber is measured indirectly via a reference table giving the temperature of the sample holder vs the heating power. This temperature is not the real surface temperature of our samples and is not directly comparable to the temperature measured in the OPUS MBE chamber. However, temperature differences observed in the two MBE systems are expected to be similar, at least over a limited range. The flux is measured by a Bayard-Alpert gauge placed behind the substrate.

\section{Results}

\section{a) Growth of CdTe/As/Si(211) and patterning of the substrate}

A 3 inch $\mathrm{Si}(211)$ wafer was cleaned using a method adapted from the RCA process. ${ }^{1}$ This method includes etching in $\mathrm{NH}_{4} \mathrm{OH}: \mathrm{H}_{2} \mathrm{O}_{2}: \mathrm{H}_{2} \mathrm{O}, \mathrm{HF}: \mathrm{H}_{2} \mathrm{O}$ and $\mathrm{HCl}: \mathrm{H}_{2} \mathrm{O}_{2}: \mathrm{H}_{2} \mathrm{O}$ solutions. It leaves a thin protective oxide (about $1 \mathrm{~nm}$ ) on the Si surface. At the end of the process, the sample was dried with nitrogen and directly transferred into the introduction chamber. The substrate was outgased in the preparation chamber for 5 hours at $500^{\circ} \mathrm{C}$ and the $\mathrm{Si}$ oxide was desorbed in the growth chamber by heating to about $1050^{\circ} \mathrm{C}$ for a few seconds. The sample was then cooled to $400^{\circ} \mathrm{C}$ under $\mathrm{As}_{4}$ flux (pressure $=5 \times 10^{-7}$ torr). At $310^{\circ} \mathrm{C}$, a CdTe nucleation layer was grown for $2 \mathrm{~min}$ (pressure $=1 \times 10^{-7}$ torr). The substrate was annealed under Te flux (pressure of $5 \times 10^{-8}$ torr) for 10 minutes at $460^{\circ} \mathrm{C}$, followed by growth of CdTe at $380^{\circ} \mathrm{C}$ for 2 hours.

The thickness, measured with the profilometer, is $2 \mu \mathrm{m}$. XRD shows a major (211) orientation and a small peak related to the (331) orientation. This is expected when CdTe is grown directly on $\mathrm{Si}(211) .^{2}$ In a separate experiment, we grew true single-crystalline $\mathrm{CdTe}(211)$ on $\mathrm{Si}(211)$ with a thin intermediate layer of ZnTe. These layers were not used for the present work; they will be used for a detailed study of the crystalline quality of CdTe grown selectively on nanoscale CdTe 
seed areas on $\operatorname{Si}(211)$.

The CdTe/As/Si(211) samples were then patterned by optical lithography. This produced islands of CdTe on the $\mathrm{Si}(211)$ substrate, as observed by SEM, SAM, XPS and Nomarski microscopy. The CdTe islands have a diameter of 80, 100, 160 and $320 \mu \mathrm{m}$ (figure 1).

\section{b) Preliminary experiment}

In order to achieve selective growth of $\mathrm{CdTe}$, one must know the highest temperature where CdTe can nucleate on $\mathrm{Si}(211)$ passivated with arsenic and the lowest temperature where CdTe desorbs from $\mathrm{Si}$. These temperatures were determined in the in-situ MBE chamber.

To determine the highest nucleation temperature of $\mathrm{CdTe}$ on $\mathrm{Si}$, the flux of $\mathrm{CdTe}$ is set to a constant value $\left(5 \times 10^{-7}\right.$ torr $)$ and a clean $\operatorname{Si}(211)$ substrate passivated with As is set to a starting temperature of $450^{\circ} \mathrm{C}$ for 30 minutes. The sample is then exposed to the CdTe flux for 2 minutes. If we do not notice any change in the RHEED pattern, the substrate temperature is decreased by $10^{\circ} \mathrm{C}$ and the experiment is repeated. By this method, we find the highest nucleation temperature of CdTe on $\operatorname{Si}(211)$ to be below $400^{\circ} \mathrm{C}$.

For the lowest desorption temperature of $\mathrm{CdTe}$, an as-grown piece of the $3 \mathrm{in} . \mathrm{CdTe} / \mathrm{Si}$ wafer is etched in a $0.1 \%$ bromine methanol solution for 5 seconds before its introduction in the in-situ UHV system. The Te-excess produced by the etching is removed by heating the substrate to $310^{\circ} \mathrm{C}$. The sample is then heated to $400^{\circ} \mathrm{C}$ for 30 minutes. If the RHEED pattern remains the same, the temperature of the sample is increased by $10^{\circ} \mathrm{C}$. The lowest desorption temperature is found when a RHEED transition is observed where the pattern changes from CdTe to $\mathrm{Si}(211)$. We determined this temperature to be $480^{\circ} \mathrm{C}$.

In conclusion, we expect it to be possible to achieve selective epitaxy of CdTe if the substrate 
temperature is between $400^{\circ} \mathrm{C}$ and $480^{\circ} \mathrm{C}$. In this case, the CdTe should stick only on the CdTe islands and not on the silicon substrate.

\section{c) Selective growth experiments}

To check this selective epitaxy process, 3 samples of patterned CdTe islands on $\mathrm{Si}(211)$ were etched in a $0.1 \%$ bromine methanol solution for 5 seconds. One was kept as reference to measure the height of the islands before the selective growth process (figure 2a). At this point, the height of the island is $0.8 \mu \mathrm{m}$. The two other samples were loaded into the in-situ UHV system. They were heated to $310^{\circ} \mathrm{C}$ to remove the Te-excess. The surface of the in-situ samples was then checked by PEEM (figure 2b). The work function of $\mathrm{SiO}_{2}$ and $\mathrm{CdTe}$ is $4.52 \mathrm{eV}$ and 5.90 $\mathrm{eV}$, respectively. Hence, with an excitation source of $4.9 \mathrm{eV}$, the CdTe islands appear black on the picture and the $\mathrm{SiO}_{2}$ is bright (we consider the work function of $\mathrm{SiO}_{2}$ because this compound was detected by AES). In order to study the selective growth, one sample was set to $400^{\circ} \mathrm{C}$ and the second one to $420^{\circ} \mathrm{C}$ while they were exposed to the same CdTe flux (pressure $=5 \times 10^{-7}$ torr) for 2 hours.

At $400^{\circ} \mathrm{C}$, the islands grow siginficantly both in diameter and in height (figure $3 \mathrm{a}$ and $3 \mathrm{~b}$ ). However, it is obvious from the PEEM images that small features appear between the islands (figure 3d). Because these features appear dark in PEEM, we suggest that they are CdTe islands that nucleate at random positions on the Si surface if it is exposed to the CdTe flux for an extended period. These structures are very rough and their height varies from 1 to $3 \mu \mathrm{m}$. For the islands, a vertical growth rate of $1.4 \mathrm{~nm} / \mathrm{s}$ was calculated from the step profile measurements. For the additional structures, the average height is $2.5 \mu \mathrm{m}$ with a standard deviation of $1.2 \mu \mathrm{m}$. In summary, although RHEED suggested that $\mathrm{CdTe}$ would not nucleate on $\mathrm{As} / \mathrm{Si}(211)$ at 
temperatures of $400^{\circ} \mathrm{C}$ or higher, this temperature is still too low to avoid deposition of CdTe on silicon. It means that the nucleation rate is very slow, but once a small structure of $\mathrm{CdTe}$ is formed on the surface, the growth rate increases because this seed acts as a preferential growth site for CdTe.

When the substrate temperature was raised to $420^{\circ} \mathrm{C}$, we only observed an increase in the height of the island (figure 4a) without any additional dark features visible by PEEM between the islands (figure $4 \mathrm{~b}$ ). The height of the island after 2 hours of growth is $1.53 \mu \mathrm{m} \pm 0.02 \mu \mathrm{m}$, confirming that CdTe indeed grew on the islands. The growth rate is much lower than at $400^{\circ} \mathrm{C}$, about $0.2 \mathrm{~nm} / \mathrm{s}$. The absence of any features in the PEEM images between the CdTe islands confirms that selective growth was achieved at $420^{\circ} \mathrm{C}$.

\section{Discussion}

We will now propose an explanation of the mechanism of selective growth based on the temperature dependence of $\mathrm{CdTe}$ growth rate. In MBE, the growth rate is conveniently measured by RHEED oscillations. Such oscillations are not observed in the case of CdTe(211)/As/Si(211), but they were used in an earlier study ${ }^{1}$ to measure the growth rate of $\mathrm{CdTe}$ on $\mathrm{As} / \mathrm{Si}(111)$.

In this study, the lowest temperature where nucleation of $\mathrm{CdTe}$ on $\mathrm{As} / \mathrm{Si}(111)$ is not observed was found to be $270^{\circ} \mathrm{C}$ based on RHEED experiments and the lowest temperature where CdTe desorbs completely from $\mathrm{Si}(111)$ was $350^{\circ} \mathrm{C}$. As we have mentioned before, these temperatures cannot be compared directly to the thermocouple readings in the present work, and we have shown in our present work that the nucleation temperature determined from RHEED experiments is not completely accurate. Yet it is significant that the difference between these temperatures is $80^{\circ} \mathrm{C}$ in both the earlier study on $\mathrm{Si}(111)$ and in our present work on $\mathrm{Si}(211)$. 
In the earlier tudy, the growth rate of CdTe was measured as a function of substrate temperature. Here, we use the model developed by Behr et al. ${ }^{1}$ for the growth of $\mathrm{CdTe}(100)$ to fit these experimental data. Their model involves two thermally activated processes, which they interpret as physisorption and chemisorption respectively. The equation, with the parameters determined from a least-squares fit to the data for $\mathrm{CdTe}(\overline{1} \overline{1} \overline{1}) \mathrm{B} / \mathrm{As} / \mathrm{Si}(111)$, is as follows:

$$
\begin{gathered}
\mathrm{R}(\mathrm{ML} / \mathrm{s})=3.46-28 \exp \left(-\mathrm{E}_{\text {phys }} / \mathrm{kT}\right)-2.23 \times 10^{15} \exp \left(-\mathrm{E}_{\text {chim }} / \mathrm{kT}\right) \\
\text { with } \mathrm{E}_{\text {phys }}=0.14 \mathrm{eV} \text { and } \mathrm{E}_{\text {chim }}=1.88 \mathrm{eV}
\end{gathered}
$$

The result is shown in figure 5.

In the case of growth of CdTe on $\mathrm{CdTe}(\overline{1} \overline{1} \overline{1}) \mathrm{B}$, each $\mathrm{Cd}$ atom has one bond with a Te atom below and three bonds with Te atoms above. For Te, the situation is the opposite. Hence, the rate limiting processes are physisorption of $\mathrm{Cd}$ on a plane of $\mathrm{Te}$ and chemisorption of Te on a plane of Cd since Cd atoms will quickly re-evaporate if they are not stabilized by Te atoms on top.

In order to understand the selectivity of growth of CdTe on $\mathrm{CdTe}(\overline{1} \overline{1} \overline{1}) \mathrm{B}$ vs. nucleation on As/Si(111), we have tried changing the activation energies in eq. (1) until we obtained a curve that would give zero growth rate at $270^{\circ} \mathrm{C}$ (lowest temperature where nucleation is not observed by RHEED on $\mathrm{Si}(111)$.) This can be achieved by reducing the chemisorption energy to about $1.55 \mathrm{eV}$, or by reducing the physisorption energy from $140 \mathrm{meV}$ to $98 \mathrm{meV}$ (dashed line in figure 5). However, it is not likely that the chemisorption enrgy changes from $1.88 \mathrm{eV}$ to $1.55 \mathrm{eV}$ when the substrate is changed from CdTe to $\mathrm{Si}$, since in both cases, Te chemisorbs on $\mathrm{Cd}$. The only difference is that $\mathrm{Cd}$ has one bond to As-Si in one case, and one bond to Te in the other. Hence we suggest that the selectivity is due to lower physisorption energy on As/Si vs. CdTe.

An ideal CdTe(211) surface is composed of steps and (111) terasses. The bonding between Cd 
and Te atoms is similar to the case of $\operatorname{CdTe}(\overline{1} \overline{1} \overline{1}) \mathrm{B}$. Hence we suggest that the explanation of selectivity between growth on $\mathrm{As} / \mathrm{Si}(211)$ and $\mathrm{CdTe}(211)$ is similar to the case of the (111) orientation. This is consistent with the measured difference between the highest nucleation temperature of CdTe on $\mathrm{Si}$ and the CdTe desorption temperature from Si for the two orientations.

\section{Conclusion}

Selective growth of CdTe on patterned $\mathrm{Si}(211)$ was achieved by MBE. First, a layer of CdTe was grwon on $\mathrm{As} / \mathrm{Si}(211)$ and a pattern was etched by optical lithography. Selective growth was obtained because CdTe does not nucleate on Si while still growing on CdTe if the substrate temperature is sufficeintly high. Based on analysis of the temperature dependence of the growth rate of $\mathrm{CdTe}(\overline{1} \overline{1}) \mathrm{B}$, we suggest that selective growth is possible because the physisorption energy is slightly smaller on Si than on CdTe.

It was shown by photoemission microscopy that the temperature for selective growth must be somewhat higher than the highest nucleation temperature for $\mathrm{CdTe}$ on $\mathrm{As} / \mathrm{Si}(211)$ determined by RHEED; otherwise, CdTe will eventually nucleate on Si between the CdTe seed areas if the substrate is exposed long enough to the CdTe flux. This suggests that, besides the simple selectivity mechanism based on physisorption energies, nucleation around defects or impurities may play a siginificant role. 


\section{Figure captions:}

Figure 1: SEM picture of CdTe islands patterned on $\mathrm{Si}(211)$

Figure 2: a) Height of CdTe island after etching CdTe/As/Si(211), measured by step profilometer b) PEEM image of patterned CdTe.

Figure 3: After growth at $400^{\circ} \mathrm{C}$ : a) height of CdTe island by step profilometer; b) PEEM image of CdTe island; c) height of additional CdTe features by step profilometer; d) PEEM image of CdTe additional features.

Figure 4: After growth at $420^{\circ} \mathrm{C}$ : a) height of CdTe island by step profilometer; b) PEEM image of CdTe island.

Figure 5: Experimental points (squares) for the growth of CdTe on $\mathrm{Si}(111)$ are fitted (straight line) by a sum of two exponential decays. The dashed line represents CdTe growing on $\mathrm{Si}(111)$ and is obtained with the same equation than the fitted straight line except that the physisorption energy is reduced from $140 \mathrm{meV}$ to $98 \mathrm{meV}$. 
Figure 1

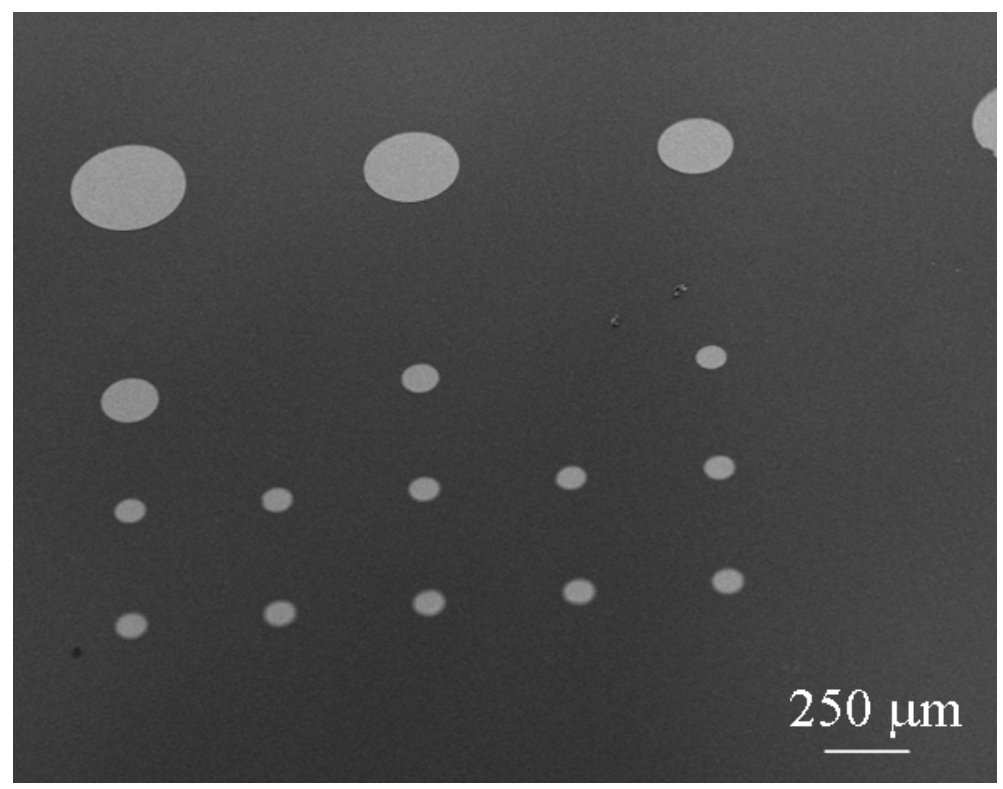


Figure 2
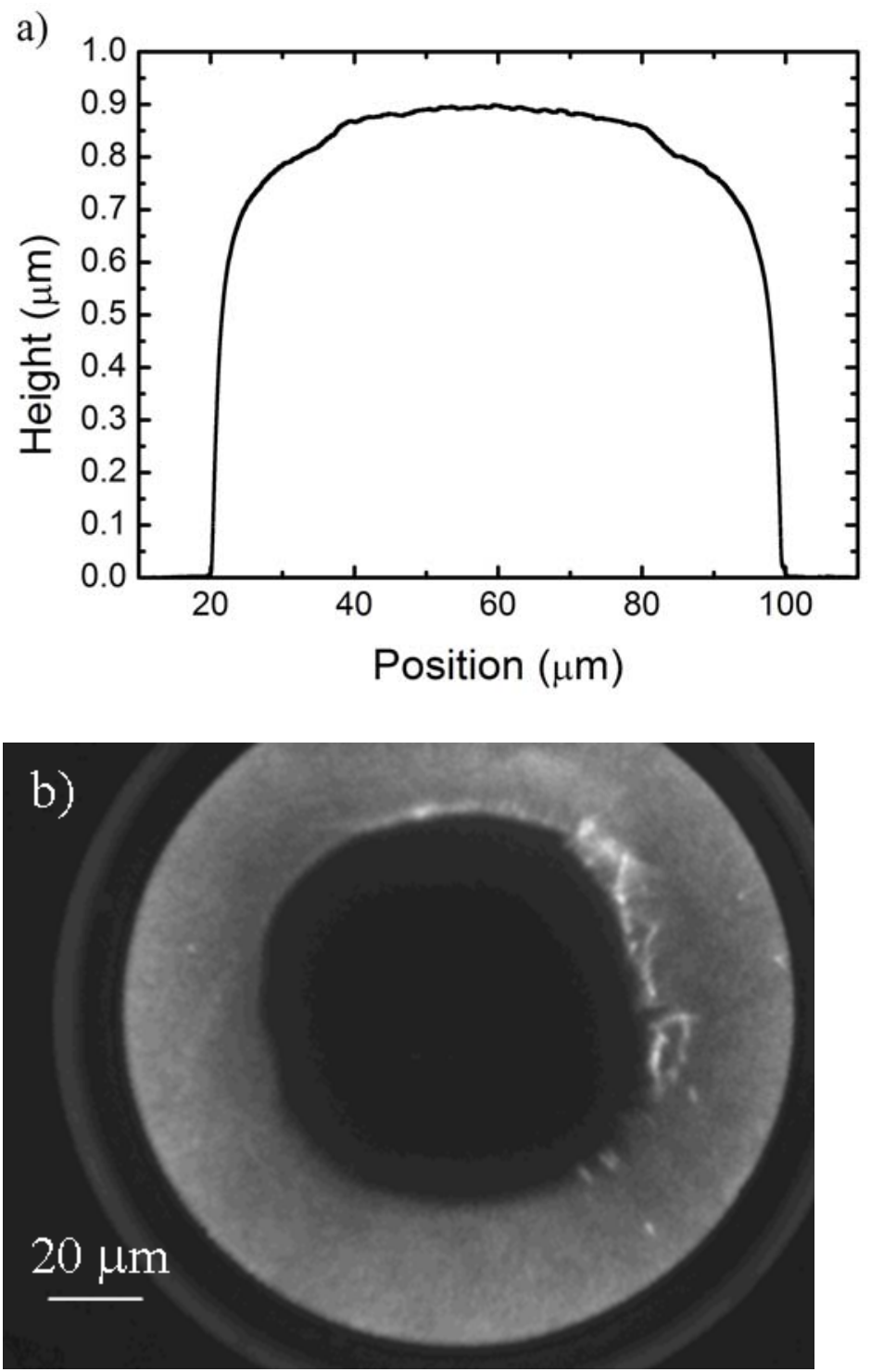
Figure 3
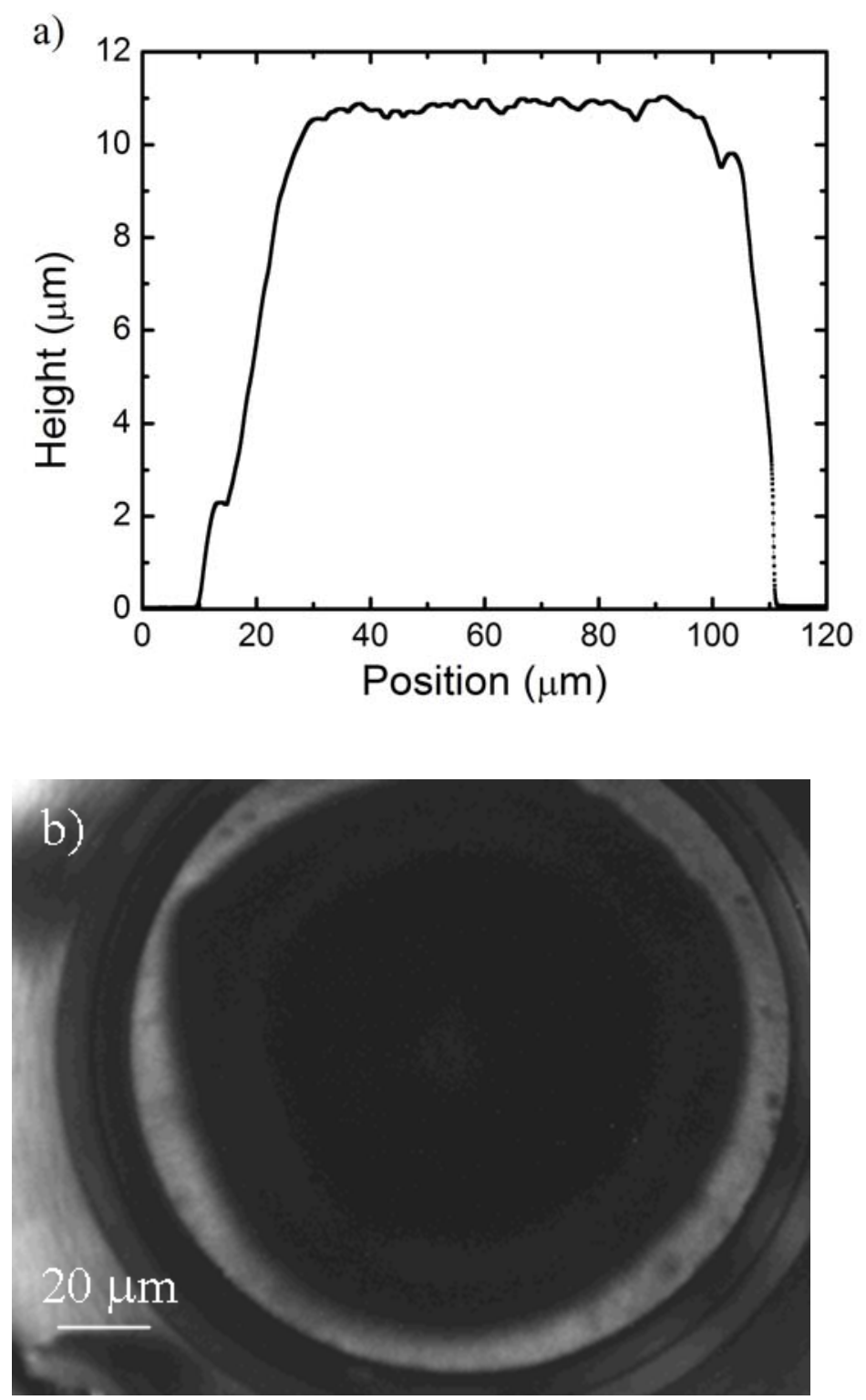

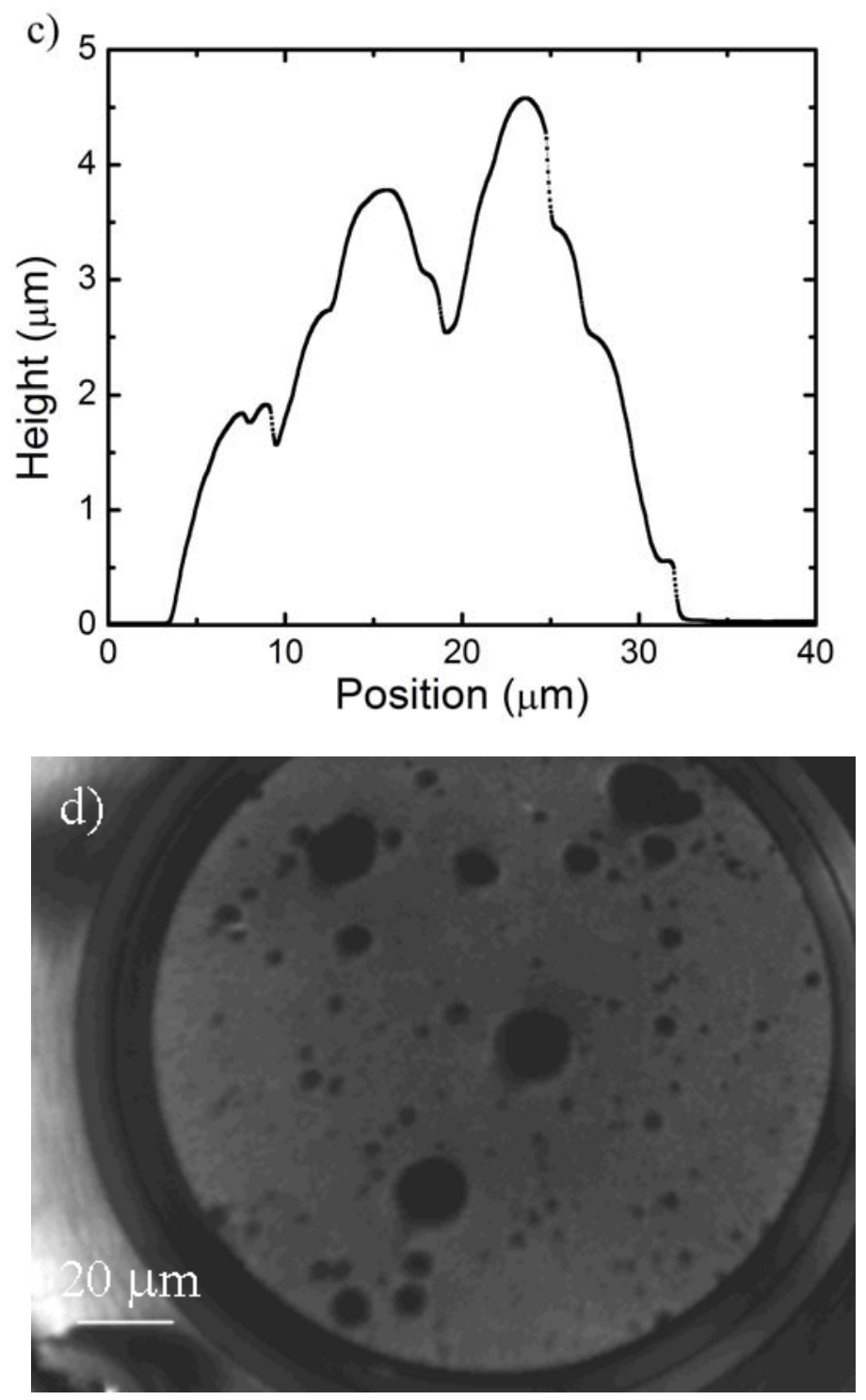
Figure 4
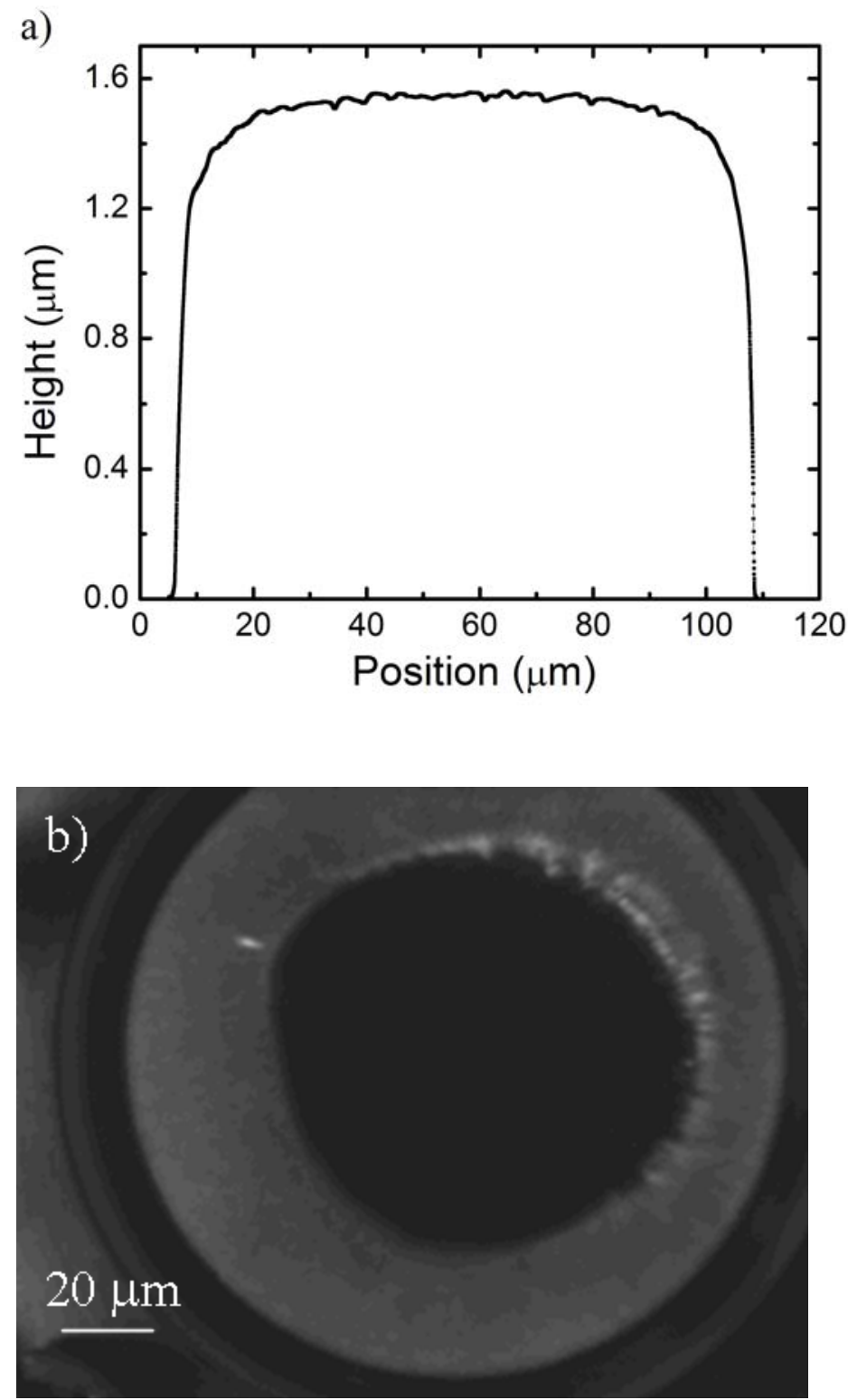
Figure 5

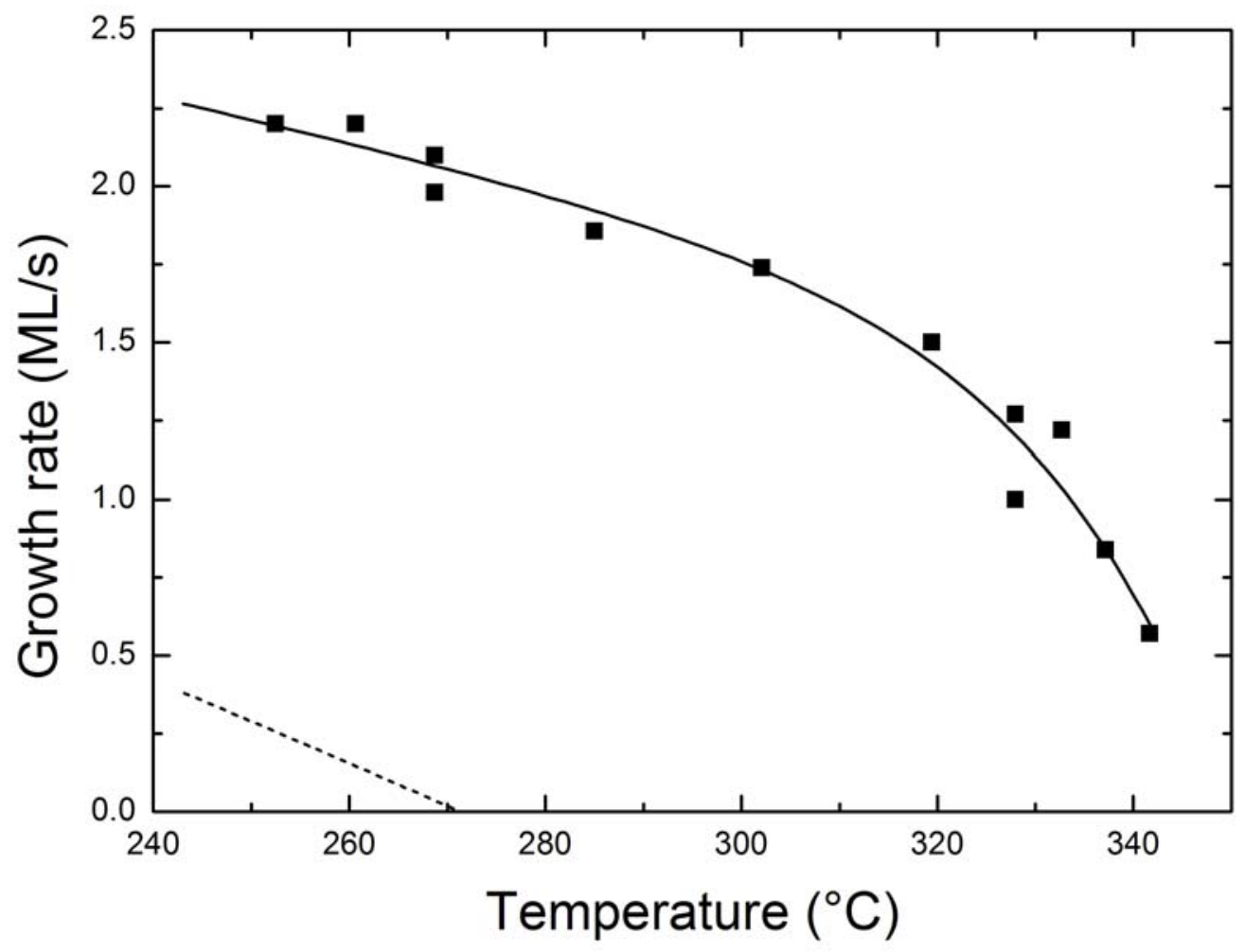


[1] S. Sivananthan, Ph.D. Thesis, University of Illinois at Chicago, Chicago, 1988

[2] R. Sporken, S. Sivananthan, K.K. Mahavadi, G. Monfroy, M. Boukerche, J.P. Faurie, Appl. Phys. Lett. 55, 1879 (1989).

[3] P.S. Wijewarnasuriya, M. Zandian, D.D. Edwall, W.V. McLevige, C.A. Chen, J.G. Pasko, G. Hildebrandt, A.C. Chen, J.M. Arias, A.I.D’Souza, J.A. Vigil, S. Rujirawat, and S. Sivananthan, J. Electron. Mat. 27, 546 (1998)

[4] T.J. de Lyon, R.D. Rajavel, J.A. Vigil, J.E. Jensen, O.K. Wu, C.A. Cockrum, S.M. Johnson, G.M. Venzor, S.L. Bailey, I. Kosai, W.L. Ahlgren, and M.S. Smith, J. Electron. Mat. 27, 550 (1998).

[5] D. Zubia, and S.D. Hersee, J. Appl. Phys. 85, 6492 (1999); D. Zubia, S.H. Zaidi, S.R.J. Brueck, and S.D. Hersee, Appl. Phys. Lett. 76, 858 (2000).

[6] S. Guha, A. Madhukar, and L. Chen, Appl. Phys. Lett. 56, 2304 (1990)

[7] K. Hiramatsu, J. Phys.: Condens. Matter. 13, 6961 (2001)

[8] I. Bhat and R. Zhang, J. Electron. Materials (2006).

[1] W. Kern, and D.A. Puotinen, RCA Rev. 31, 187 (1970).

[2] S. Rujirawat, L. A. Almeida, Y. P. Chen, S. Sivananthan, D. J. Smith, Appl. Phys. Lett. 71, 1810 (1997).

[1] R. Sporken, D. Grajewski, Y. Xin, F. Wiame, G. Brill, P. Boieriu, A. Prociuk, S. Rujirawat, N.K. Dhar, and S. Sivananthan, J. Elec. Mat. 26, 760 (2000).

[1] T.Behr, T. Litz, A. Waag, G. Landwehr, Journal of Crystal Growth 156, 206 (2000) 